\title{
STUDY OF SOME MOLECULAR MARKERS ASSOCIATED WITH REPRUCTIVE PERFORMANCE OF APRI LINE, BALADI BLACK AND NEW-ZELAND WHITE RABBITS
}

\author{
A.F. Ashour and S.M. Shamia \\ Animal Production Research Institute, Agricultural Research Center, Ministry of Agriculture, \\ Dokki, Egypt
}

\section{SUMMARY}

Random amplified polymorphic DNA (RAPD), using 15 arbitrary primers, was used to investigate three rabbit genotypes namely Animal Production Research Institute (APRI) line, Baladi Black breed (BB) and New-Zealand White breed (NZW) to detect molecular genetic markers which could be used to distinguish among the studied genotypes. Moreover associations between theses markers and the studied genotypes reproductive performance traits (Litter size, living litter size, birth weight and birth litter size) were performed. DNA banding pattern indicated that APRI line did not give any band reaction with primers OPA2 and OPA7, while the other two genotypes gave two distinct bands at least. So, these primers could be used as associated markers for litter size, living litter size, and birth litter size traits. The result of RAPD patterns generated, in total, 104 bands, out of them 62 were polymorphic. APRI line and $(B B)$ genotypes shared most of the bands. This support their similar origin, since they have the same common ancestors. However, the other genotype (NZW) has different pattern than other genotypes. The phylogenetic tree indicated that both genotypes APRI line and (BB) were highly similar than (NZW) which was highly diverged than other genotypes. This investigation indicates that RAPD markers could be used to characterize genetically different rabbits and indicate association with some reproductive performance.

Keyword: rabbit, molecular genetics marker, RAPD, reproductive traits, phylogenic tree.

\section{INTRODUCTION}

Rabbits are considered as a source of meat production in Egypt through developing animal production using semi-ruminant species. FAO (1981) stated that rabbits, which fall under the previous group, as short-cycle animals, have the ability to be a source of meat, by increasing their production.

Reproduction is essential for all species as it is the key for survival and evolution. Overall processes of sexual reproduction are relatively conserved and well defined, but the underlying molecular and genetic basis of each of the numerous steps involving these general processes is much less known. The complexity and transient nature of specific reproductive processes are the cause of reduced knowledge concerning their molecular basis.

Recently, a synthetic paternal rabbit line, named Alexandria, was originated by crossing a V-line with a Baladi Black rabbits. Individual selection for daily gain from weaning (28 days) to slaughter age (63 days) was used as a selection criterion for the genetic improvement for this line (El-Raffa, 2005 and 2007).

From a productive point of view, reproductive efficiency is one of the most important factors affecting productivity in livestock industries. Reproductive traits, especially those related with fertility, litter size and pre-weaning viability, are important components for reducing the costs of producing animal meat (De Vries, 1989; Rothschild and Bidanel, 1998). Therefore, much effort is made to identify the ways for improving these traits. This improvement of reproductive traits is related to different fields, with management, nutrition and genetics having a great impact.

(RAPD) analysis has become common technique for identifying the markers linked to traits of interest without the necessity for mapping the entire genome (Bardakci, 2001). These markers have been used for genotype identification (Tinker et al., 1993), construction of genetic maps (Maddox and Cockett, 2007), analysis of the genetic within and among populations (Tsuda et al., 2001; Hardy et al., 2006), and in detecting polymorphism in different poultry species (Salem et al., 2005).

In this concept, Williams et al. (1990) introduced the DNA polymorphisms amplified by arbitrary primers as genetic markers to be used in genetic maps and the use of this type of markers increased rapidly. Simplicity, applicability and low cost of the RAPD technique gave this technique wide range of applications in many areas of genetics and molecular biology. Also, RAPD technique provides a useful approach for evaluating genetic differences particularly in species that are poorly known genetically (Sale et al., 1996 and Wen and Hsiao, 1999), in genetic identification 
(Kresovich et al., 1992), in introgression studies (McCoy and Echt, 1993), in parental test (Welsh et al., 1991).

The aim of this study was to investigate the association between markers and reproductive performance in three rabbit breed APRI line, (BB) and (NZW) breed using RAPD technique.

\section{MATERIALS AND METHOD}

The present study was conducted at the rabbit of the Animal Production Research Station Sakha, Animal Production Research Institute, Agriculture Research Center, Egypt. This study aimed to evaluate the reproductive and molecular traits in the APRI line, (BB) and NZW rabbit breed.

\section{Animal Production Research Institute (APRI) line:}

This line was developed at the Animal Production Research Institute in Egypt. The first step of development was to get an F1 from crossing Red Baladi bucks with does of $\mathrm{V}$ line. The procedure continued getting F1, F2, F3 and so on. After F3, the animals were named APRI line. In this line, the proportion of genes is $50 \%$ from $\mathrm{V}$ line and $50 \%$ from Red Baladi. The $\mathrm{V}$ line is maintained at the stations Sakha and Gimmiza and selected for litter weight at weaning. The Institute also keeps the APRI line at Sakha Station and was selected for the high litter weight at weaning.

\section{Baladi Black (BB):}

It is a local Egyptian breed; it was founded at the Poultry Breeding Section stations, Ministry of Agriculture (Egypt) through crossbreeding for several generations between native rabbits and Flemish Giant (Badawy, 1975 and Galal \& Khalil, 1994).

New Zealand White (NZW):
A foreign breed actually originated in the United States and it is wide spread all over the world.

\section{Reproductive data recording:}

Doe reproductive performance and the data of 256 litter (69 litters from APRI strains, 87 litters from New Zealand white (NZW) and 100 litters from Baldi Black (BB) were recorded throughout the breeding seasons. Day of delivery, gestation period, number of total born and born-alive per delivery, litter weight of born alive, litter size and weight at $21 \mathrm{~d}$ of age, preweaning mortality, and both litter size, and weight at weaning were also recorded.

The following data were then calculated: conception rate (number of service pregnancy), fertility rate (percentage of deliveries/mating), viability rate at birth (number of live born/total number of kids $X$ 100), individual weight of born alive, at $21 \mathrm{~d}$ of age, and at weaning.

\section{Blood sample collection and DNA extraction:}

Individual blood samples were collected from the vein near the ear edge in $3 \mathrm{ml}$ vacationer tube included EDTA K3. DNA of collected blood samples were extracted from the whole blood using the E.Z.N.A. Blood DNA Midiprep Kits following the manufacture instructions (Omega Bio-tek 400 Pinnacle Way, Suite 450 Norcross, GA 30071 USA).

$P C R$ reaction and separation of $R A P D$ product:

The PCR reactions using 15 arbitrary oligonucleotide primers (10-mer) that were used in this study are shown in Table (1). The reactions were optimized and mixtures were prepared according to (Keliang et al., 2008) The PCR products were separated by electrophoresis using $1.2 \%$ agarose gel in $0.5 \mathrm{x}$ TBE buffer against $100 \mathrm{bp}$ DNA Ladder as a size marker. Bands were detected with ethidium bromide staining and documented on Gel Documentation.

Table 1. List of Primers used for RAPD analysis and their nucleotide sequences

\begin{tabular}{|c|c|c|}
\hline S. No. & Primer code & Sequence \\
\hline 1 & OPA1 & 5'-ACA GGT GCT G-3' \\
\hline 2 & OPA2 & 5'-ACG CCA GAG G-3' \\
\hline 3 & OPA3 & 5'-ACG GCG TAT G-3' \\
\hline 4 & OPA4 & 5'-CAG ACA AGC C-3' \\
\hline 5 & OPA5 & 5'-CAG CTC ACG A-3' \\
\hline 6 & OPA6 & 5'-CCC AGC TAG A-3, \\
\hline 7 & OPA7 & 5'-TGG CGC AGT G-3' \\
\hline 8 & OPA8 & 5'-CTG GGC ACG A-3' \\
\hline 9 & OPA9 & 5'-GAC TAG GTG G-3' \\
\hline 10 & OPA10 & 5'-GGT CTA CAC C-3' \\
\hline 11 & OPA11 & 5'-GTC GCC GTC A-3' \\
\hline 12 & OPA12 & 5'-TGC GCC CTT C-3' \\
\hline 13 & OPA13 & $5^{\prime}$-СТT CCC CAA G-3' \\
\hline 14 & OPA14 & 5'-TTC CGC CAC C-3' \\
\hline 15 & OPA15 & 5'-TTC GAG CCA G-3' \\
\hline
\end{tabular}




\section{Data Analysis:}

Amplification profiles for the tested genotypes as a result of RAPD application were compared with each other and DNA fragments were scored as a binary data. The electrophoretic patterns of the reproducible banding patterns of each primer which were produced by RAPD were chosen for analysis. Each band was scored as present (1) or absent (0), and pairwise comparisons between individuals were made to calculate the JukesCantor coefficient using PAST program (PA leontological Statistics Version 1.94b) adapted by Hammer et al. (2001). Cluster analysis was performed to produce a denderogram using unweighted pair-group method with arithmetical average (UPGMA) algorithm (Santi, 2002).

\section{RESULTS AND DISSECTION}

Reproductive performance of does:

Data presented in Table (2) show the reproductive performance of the three rabbit breeds (APRI Line, Baldi Black (BB) and New Zealand White (NZW)). Total litter size, born alive, total weight at birth, litter size at $21 \mathrm{~d}$ and total weight at 21d were significantly $(\mathrm{P}>0.001)$ higher in APRI line than in other two breed, however the same traits were significantly $(\mathrm{P}>0.001)$ higher in $(\mathrm{NZW})$ than in Baldi Black rabbit. While, weight at birth was significantly $(\mathrm{P}>0.042)$ higher in $(\mathrm{NZW})$ $(54.09 \mathrm{~g})$ than in APRI line (51.94 g) and Baldi Black (52.01 g) Table (2).

On the other hand, litter size at weaned, weaning weight and total weaning weight were significantly $(\mathrm{P}>0.001)$ higher in APRI line than in other two breed.

Table 2. Main effect of breed on rabbit reproductive performance

\begin{tabular}{lcccc}
\hline Parameters & $\begin{array}{c}\text { New Zealand } \\
\text { White (NZW) }\end{array}$ & APRI Line & Baldi Black (BB) & $\begin{array}{c}\text { Level of } \\
\text { significant }\end{array}$ \\
\hline Total litter size at birth (n) & $6.82 \pm 0.13^{\mathrm{b}}$ & $7.65 \pm 0.22^{\mathrm{a}}$ & $6.25 \pm 0.18^{\mathrm{c}}$ & 0.001 \\
Born alive (n) & $6.56 \pm 0.12^{\mathrm{b}}$ & $7.43 \pm 0.21^{\mathrm{a}}$ & $5.99 \pm 0.16^{\mathrm{c}}$ & 0.001 \\
Weight at birth (g) & $54.09 \pm 0.79^{\mathrm{a}}$ & $51.94 \pm 0.80^{\mathrm{b}}$ & $52.01 \pm 0.48^{\mathrm{b}}$ & 0.042 \\
Total weight at birth (g) & $356.24 \pm 9.14^{\mathrm{b}}$ & $383.69 \pm 9.93^{\mathrm{a}}$ & $310.32 \pm 8.52^{\mathrm{c}}$ & 0.001 \\
Litter size at 21d (n) $_{\text {Weight at 21d (g) }}^{5.24 \pm 0.13^{\mathrm{b}}}$ & $6.23 \pm 0.17^{\mathrm{a}}$ & $4.61 \pm 0.17^{\mathrm{c}}$ & 0.001 \\
Total weight at 21d (g) & $235.9 \pm 4.27^{\mathrm{b}}$ & $240.22 \pm 6.55^{\mathrm{ab}}$ & $253.89 \pm 4.61^{\mathrm{a}}$ & 0.024 \\
Litter size at weaneing (n) & $1228.85 \pm 34.13^{\mathrm{b}}$ & $1482.85 \pm 51.78^{\mathrm{a}}$ & $1118.55 \pm 32.99^{\mathrm{c}}$ & 0.001 \\
Weaning weight $(\mathbf{g})$ & $4.44 \pm 0.15^{\mathrm{b}}$ & $5.36 \pm 0.17^{\mathrm{a}}$ & $4.07 \pm 0.16^{\mathrm{b}}$ & 0.001 \\
Total weaning weight (g) & $544.0 \pm 10.19^{\mathrm{a}}$ & $479.8 \pm 11.18^{\mathrm{b}}$ & $565.01 \pm 10.72^{\mathrm{a}}$ & 0.001 \\
\hline
\end{tabular}

\section{Detection of genetic variation among rabbit} genotypes using RAPD's markers:

On the basis of these characteristics, two different approaches were used to extract statistical information from the RAPD data. The first one corresponds to the direct study of RAPD bands presence or absence. We will refer to it as the 'band-based' approach. The second one, that we call the 'allele frequency-based' approach, consists of estimating allelic frequencies, at each locus, which appear from polymorphic percentage. This will be used to survey genetic diversity or differentiation with classical population genetics methods.

Arbitrary primers complement different parts of the genomic DNA. PCR products differ in band number and size. In this study, 15 primers were used to assess the genetic variability among the three rabbit genotypes (Figure 1) it generated a total of 104 bands. Sixty two bands $(59.61 \%)$ were polymorphic; however, forty two bands were monomorphic (common) for all genotypes. The highest level of polymorphism $(100 \%)$ was observed in primer OPA2 and OPA7. The APRI genotype did not give any band reaction with this primer. However, the other two genomes gave at least two distinct bands. Thus, we could use these primers for litter size traits and associated marker for this character. Moreover, the lowest level of polymorphism was $40 \%$, associated with primer OPA14 as shown in Table (3). RAPDPCR fingerprints have been successfully used in defining genetic diversity among different species of horse, buffalo, beef, venison, rabbit, and kangaroo (Yang et al., 2013).

So, we could consider the RAPD as primary molecular marker to study the association between rabbit populations and some reproductive traits like litter size, living litter size, and birth litter size. This is indicated by the absence and presence of some bands.

Primers OPA2 and OPA7 showed the highest polymorphism while primer OPA14 showed the lowest polymorphism. TNB, total number bands; $\mathrm{PB}$, polymorphic bands; MP, monomorphic bands; $\mathrm{P} \%$, polymorphism

\section{Genetic relationships among the studied rabbit genotypes:}

The obtained variations from RAPD analysis was used to construct phylogenetics tree (Table 4 and Figure 2) based on the amount of shared alleles between all pairs of individuals. The results indicated that the similarity index was so high within each group for example it was $97 \%$ within BB group followed by $94 \%$ within NZW group and $93 \%$ within APRI group. Furthermore, 
Table 3. Numbers and types of the amplified DNA bands as well as the total polymorphism percentage obtained by using the 15 selected RAPD primers

\begin{tabular}{ccccc}
\hline Primer code & TNB & PB & MB & $\%$ P \\
\hline OPA1 & 6 & 5 & 1 & 83.30 \\
OPA2 & 6 & 6 & 0 & 100.0 \\
OPA3 & 6 & 3 & 3 & 50.00 \\
OPA4 & 4 & 2 & 2 & 50.00 \\
OPA5 & 12 & 5 & 7 & 41.00 \\
OPA6 & 7 & 4 & 3 & 57.00 \\
OPA7 & 4 & 4 & 0 & 100.0 \\
OPA8 & 9 & 4 & 5 & 44.4 .0 \\
OPA9 & 9 & 4 & 5 & 44.4 .0 \\
OPA10 & 9 & 6 & 3 & 66.66 \\
OPA11 & 7 & 5 & 2 & 71.42 \\
OPA12 & 6 & 4 & 2 & 66.66 \\
OPA13 & 7 & 4 & 3 & 57.14 \\
OPA14 & 5 & 2 & 3 & 40.00 \\
OPA15 & 7 & 4 & 3 & 57.00 \\
Total & 104 & 62 & 42 & 59.61 \\
\hline
\end{tabular}
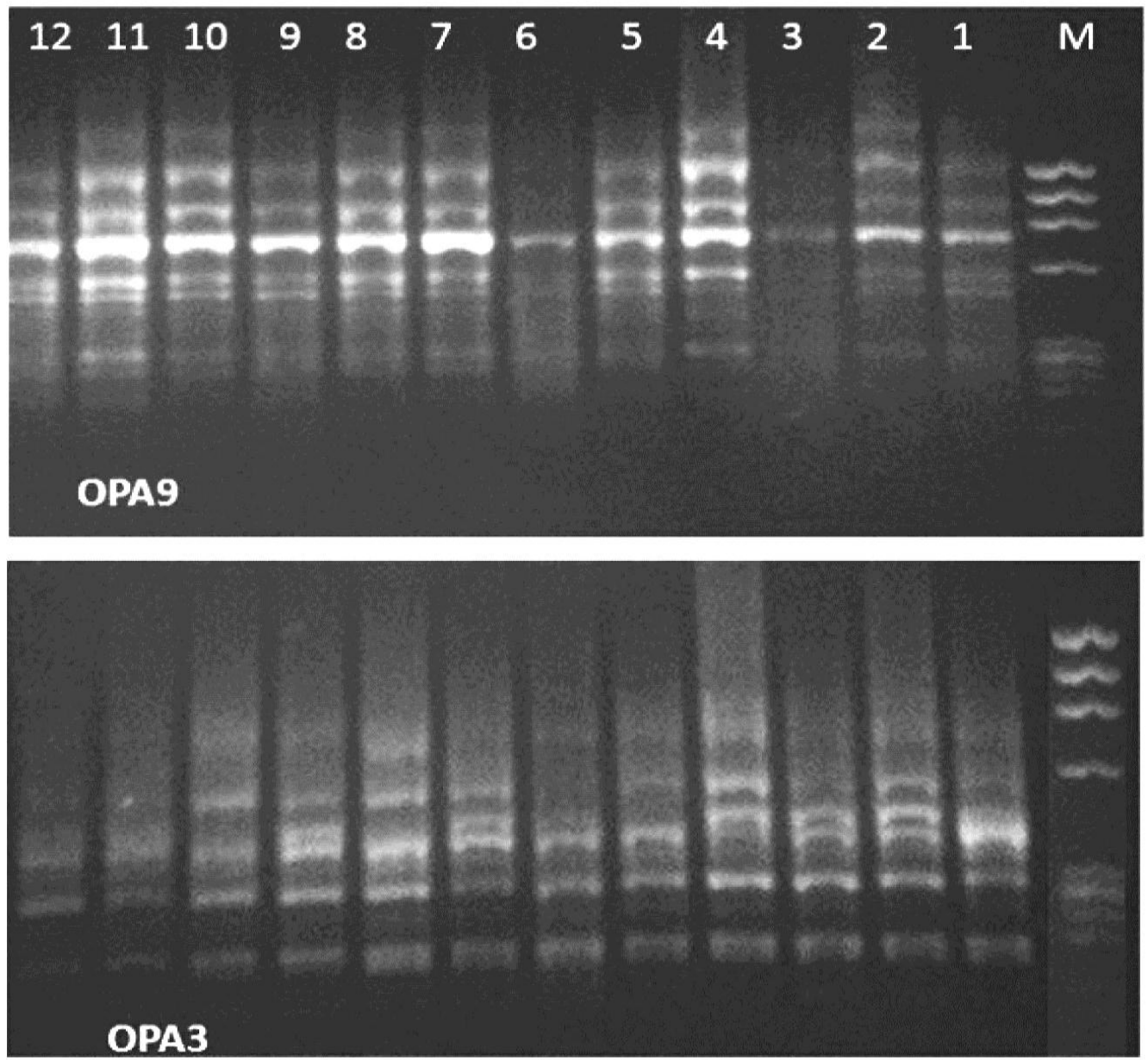

Figure 1. RAPD banding patterns of the three rabbit genotypes for the tow primers OPA9 and OPA3 Lanes from: 1 to 4 represent APRI line (lane 1 Sir, 2,3,4 daughters), 5 to 8 NZW breed (lane $5 \mathrm{Sir}, 6,7,8$ daughters) and from 9 to $12 \mathrm{BB}$ breed (lane 9 Sir10,11,12 daughters) and (M) stander marker 100 bp ladder.

the lowest similarity was between APRI and NZW with similarity $68 \%$. APRI genotypes (male and its related females) were closely related to each other and core close to the $\mathrm{BB}$ breed, while the NZW genotypes were the most different and highly diverged from the other two breeds. This may be due to the fact that the BB and APRI are Egyptian genotypes. This result is constant out with the performance results for litter size at weaning. This is in agreement with 
Keliang et al. (2008) who found that RAPD marker correlated with reproductive performances in Rex Rabbit. These results indicated that RAPD primers revealed a kind of genetic diversity among these genotypes, which suggested that RAPD markers can be used as a tool to understand the genetic variability and phylogenetic relationship among rabbit genotypes.

Knowledge of the genetic distances among different genotypes is very useful for the genetic improvement (Ceron and Angel, 2001). The similarity index was $68 \%$ as the lowest values between APRI and NZW genotypes indicating that they are highly diverged. However the highest value was $97 \%$ between BB and NZW as showed in Table (4) which they are mixed clustering in the dendogram Figure (2).

Similarity among the three rabbit genotypes represent: APRI (Sir), (APRI 1, APRI 2 and APRI 3 daughters), BB (Sir), (BB 1, BB 2 and BB 3 daughters) and NZW (Sir), (NZW 1, NZW 2 and NZW 3 daughters).

RAPD based dendogram of the three rabbit genotypes constructed using unweight pair-group arithmetic average (UPGMA) and similarity matrices.

Table 4. Similarity matrix among the rabbit genotypes based on RAPD analysis

\begin{tabular}{|c|c|c|c|c|c|c|c|c|c|c|c|}
\hline 0 & APRI & APRI 1 & APRI 2 & APRI 3 & $\mathrm{BB}$ & BB 1 & BB 2 & BB 3 & NZW & NZW 1 & NZW 2 \\
\hline APRI 1 & 0.88372 & 1 & & & & & & & & & \\
\hline APRI 2 & 0.92683 & 0.85 & 1 & & & & & & & & \\
\hline APRI 3 & 0.91304 & 0.93333 & 0.88372 & 1 & & & & & & & \\
\hline BB & 0.85 & 0.76923 & 0.86486 & 0.80952 & 1 & & & & & & \\
\hline BB 1 & 0.7027 & 0.69667 & 0.76471 & 0.69667 & 0.84848 & 1 & & & & & \\
\hline BB 2 & 0.71429 & 0.78049 & 0.71795 & 0.81818 & 0.84211 & 0.85714 & 1 & & & & \\
\hline BB 3 & 0.74419 & 0.7619 & 0.75 & 0.84444 & 0.87179 & 0.83333 & 0.97561 & 1 & & & \\
\hline NZW & 0.71429 & 0.78049 & 0.71795 & 0.81818 & 0.84211 & 0.8 & 0.95 & 0.97561 & 1 & & \\
\hline NZW 1 & 0.82609 & 0.84444 & 0.7907 & 0.91667 & 0.85714 & 0.76923 & 0.91909 & 0.93333 & 0.90909 & 1 & \\
\hline NZW 2 & 0.73171 & 0.75 & 0.68421 & 0.74419 & 0.81081 & 0.82353 & 0.92308 & 0.9 & 0.92308 & 0.83721 & 1 \\
\hline NZW 3 & 0.76923 & 0.73684 & 0.72222 & 0.68293 & 0.85714 & 0.875 & 0.86486 & 0.84211 & 0.86486 & 0.78049 & 0.94444 \\
\hline
\end{tabular}

\begin{tabular}{|c|c|c|c|c|c|c|c|}
\hline \multicolumn{8}{|c|}{ S im ila rity } \\
\hline 울 & 㞼 & 음 & 웅 & 옹 & $\ddot{8}$ & 옹 & 8 \\
\hline
\end{tabular}

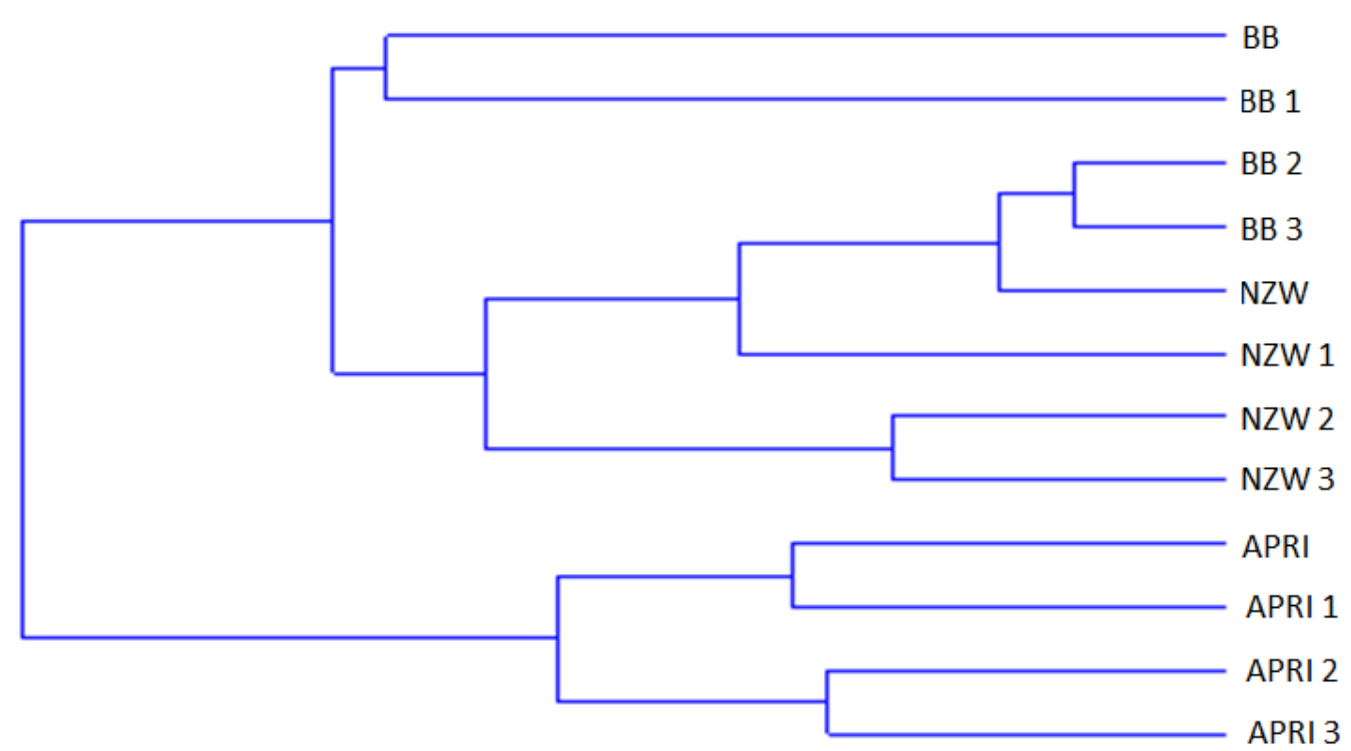

Fig. 2.Dendrogram showing genetic relationships among the three rabbit genotypes based on similarity indices derived from RAPD analysis using UPGMA software

From the dendogram APRI was clustered on a separate group, which could indicate that this line has differed out characteristics as showed in Table (4).
RAPD markers have been used for genotype identification (in rabbits: Khalil et al., 2008 and Galal, Ola et al., 2013; in chicken: Ghanem, Hanan et al., 2012). 
These results revealed high level of homogeneity among the individuals of these lines on the molecular level since almost all the 15 used primers showed high common bands among the studied individuals. RAPD-PCR provides a highly effective method for identifying the markers linked to traits of interest without the necessity for mapping the entire genome (Bardakci, 2001) and also in the discrimination of genetic resources that are economically important such as poultry and farm animals (Nikkhoo et al., 2011). Similar, results were reported in four different rabbit genotypes (Galal, Ola et al., 2013).

\section{CONCLUSION}

The present study is a preliminary step to generate RAPD markers in a new synthetic paternal rabbit line called APRI and to try to find marker associated with productive performance. These markers represent reliable tools for characterization and genetic improvement of rabbits under Local breeding conditions in Egypt. From DNA banding pattern we can concluded that APRI genotype did not give any band reaction with the OPA2 and OPA7 primers. The other two genomes gave at least two distinct bands. Thus, we could use these primers for litter size, living litter size, and birth litter size traits and associate these markers with these characters. Moreover, RAPD analysis can be successfully applied to study genetic diversity and relationships among the three genotypes. This could have a great impact on rabbit breeding programs.

\section{REFERENCES}

Badawy, A.G., 1975. "Rabbit Raising", 2nd Edition, Central Administration for Agricultural Culture, Ministry of Agriculture, Egypt.

Bardakci, F., 2001. Random Amplified Polymorphic DNA (RAPD) Markers. Turkish Journal of Biology, 25, 185-196.

Ceron, A., and Angel, F., 2001. Genetic diversity in sugarcane hybrids in Colombia measured using molecular markers. Proc. Int. Soc. Sugarcane Technol. of North America, 24: 626.

De Vries, A.G., 1989. A model to estimate economic values for traits in pig breeding. Livestock Production Science. 21:49-66.

El-Raffa, A. M., 2005. "Genetic analysis for productive and reproductive traits of $\mathrm{V}$ line rabbits raised under Egyptian conditions",Egyptian Journal of Poultry Science, Vol. 25,No. IV, pp. 1217-1231.

El-Raffa, A. M., 2007. Formation of a rabbit synthetic line (Alexandria line) and primary analysis of its productive and reproductive performance, Egypt Poultry Science, Vol. 27, No. II, pp. 321-334.

FAO, 1981. Expert conclusion on rural poultry and rabbit production, FAO secretariat, Rome.

Galal, E. S. E., and M. H. Khalil, 1994. Development of rabbit industry in Egypt, Options Mediterranean's, Series Cahiers, Vol. 8, pp. 43-56.

Hammer, Ø., Harper D.A.T. Harper., and Ryan, P.D., 2001. Paleontological Statistics Software Package for Education and Data Analysis, Palaeontologia Electronica, 4: 1-9.

Ghanem, H. Hanan., Y.A. Attia, W. S. ElTahawy and A.N. Nawar, 2012. Developing a three-way cross of chickens for improving egg production traits, Heterosis effect and analysis of DNA polymorphism using RAPDPCR. Egypt. Poult. Sci., Vol. 32, No. IV, pp. 833-849.

Hardy, O.J., Maggia, L., Bandou, E., Breyne, P., H. Caron, M.H. Chevallier, A. Doligez, C. Dutech, A. Kremer, C. Latouche-Halle, V. Troispoux and V.B. Veron Degen, , 2006. Fine-scale genetic structure and gene dispersal inferences in 10 Neotropical tree species, Molecular Ecology, Vol. 15, No. 2, pp. 559-571.

Khalil, M.H., M.I. Motawei, A.M. Saef, K.A. Al-Sobayil and M.F. El-Zarei, 2008. RAPD Markers Linked To Litter, Lactation and Growth Traits In Rabbits. WRSA - 9th World Rabbit Congress, 10-13 June, Verona (Italia), G45.

Keliang, R., L. Yanping, H. Dongchang, W. Xinsheng, , Z. Ping, L. Quanzhong, Z. Lijun, Z. Shenghua, and C. Liang, 2008. Study on relationship of Rex rabbit RAPD marker and reproductive performances. $9^{\text {th }}$ World Rabbit Congress, June 10-13, Verona, Italy.

Kresovich, S., J.G.K. Williams, J.R. Mcferson, E.J. Routman and B.A. Schall, 1992. Characterization of genetic identities and relationships of Brassica oleracea L. via a random amplified polymorphic DNA assay. Theor. Appl. Genet., 85, 190-196.

Maddox, J. F., and N. E. Cockett, 2007. An update on sheep and goat linkage maps and other genomic resources. Small Ruminant Research, Vol. 70, pp. 4-20.

McCoy, T.J. and C.S. Echt, 1993. Potential of trispecies bridge crosses and random amplified polymorphic DNA markers for introgression of Medicago daghestanica and M. pironae germplasm into alfalfa (M. sativa). Genome, 36, 594-601.

Nikkhoo, M., S. Hadi, R. Ghodrat, N. Mozhdeh, F. Farnaz and K. Minoo, 2011. Measurement of genetic parameters within and between breeder flocks of Arian broiler lines using randomly amplified polymorphic DNA (RAPD) markers. African journal of 
Biotechnology, Vol. 10, No. 36, pp. 68306837.

Galal, A. Ola., M. Rehan and AbdEl-Karim E. Ragaa, 2013. Analysis of genetic diversity within and among four rabbit genotypes using biochemical and molecular genetic markers. Academic Journals, Vol. 12, No. 20, pp. 2830-2839.

Rothschild, M.F. and J.P. Bidanel, 1998. Biology and Genetics of Reproduction. Pages 313343 in The Genetics of the Pig. M. F. Rothschild and A. Ruvinsky, ed. CAB Int., Univ. Press, Cambridge, U.K.

Sale, M. M., B.M. Potts and A.K. West, 1996. Molecular differentiation within and between Eucalyptus risdonii, E. amygdalina and their hybrids using RAPD markers. Australian Journal of Botany, 44, 559-569.

Salem, H. H., B. A. Ali, T. H. Huang and D. N. Qin, 2005. Use of randomly amplified polymorphic DNA (RAPD) markers in poultry research", Int. J. Poult. Sci., Vol. 4, No. 10, pp. 804-811.

Tinker, N.A., M.G. Fortin and D.E. Nather, 1993. Random amplified polymorphic DNA and pedigree relationships in spring barley. Theoretical and applied genetics, Vol. 85, pp. 976-984.

Tsuda, Y., S. Goto and Y. Ide, 2001. RAPD analysis of genetic variation within and among four natural populations of Betula maximowieziana. Silvae Genet., Vol. 53, pp. 234-239.
Welsh, J., R.J. Honeycutt, M. McClelland and B.W.S. Sobral, 1991. Parentage determination in maize hybrids using the arbitrarily primed polymerase chain reaction (AP-PCR). Theoretical and Applied Genetics, 82, 473-476.

Wen, C.S., and J.Y. Hsiao, 1999. Genetic differentiation of Lilium longiflorum Thunb. var. scabrum Masam. (Liliaceae) in Taiwan using Random Amplified Polymorphic DNA and morphological characters. Botanical Bulletin of Academia Sinica, 40, 65-67.

Williams, J.G.K., A.R. Kubelik, K.J. Livak, J.A. Rafalski and S.V. Tingey, 1990. DNA polymorphisms amplified by arbitrary primers are useful as genetic markers. Nucleic Acids Research, 18, 6531-6535.

Yang, W., X. Kang, Q. Yang, Y. Lin and M. Fang, 2013. Review on the development of genotyping methods for assessing farm animal diversity. J. Anim. Sci. Biotechnol. 4(1):2.

Santi Garcia-Vallvé, 2002. DendroUPGMA software: A dendrogram construction utility that uses Pearson coefficients and the UPGMA algorithm, Evolutionary Genomics Group, Biochemistry and Biotechnology Department. Universitat Rovira i Virgili (URV), Tarragona, Spain. http://genomes.urv.es/UPGMA/.
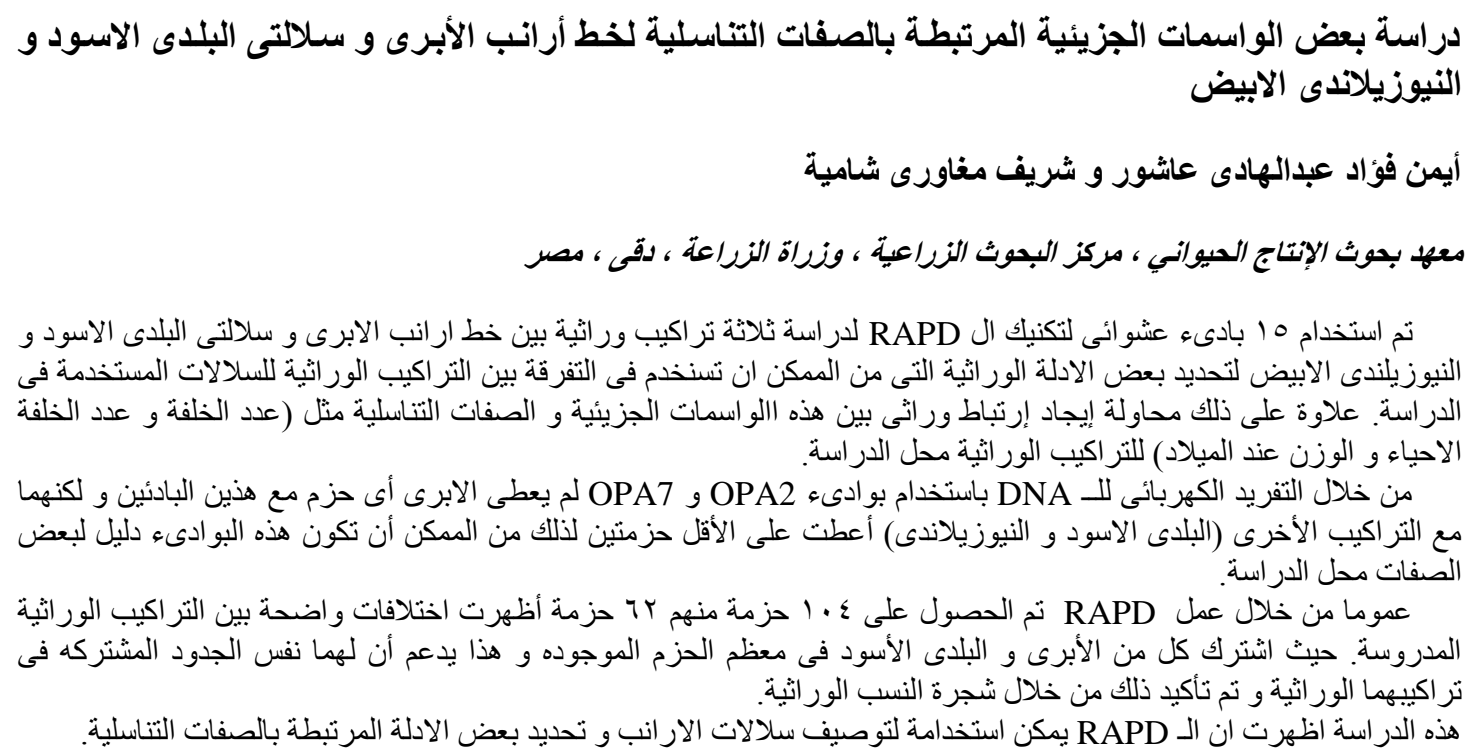